\title{
HSE CHEMISTRY
}

\section{MAKESE EMENTS}

\section{WORK FORSYOU}

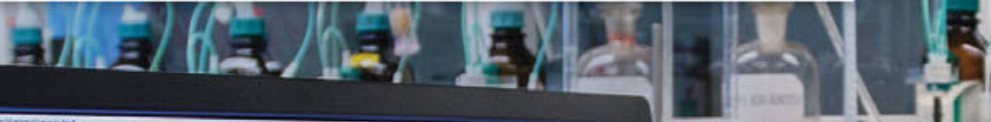

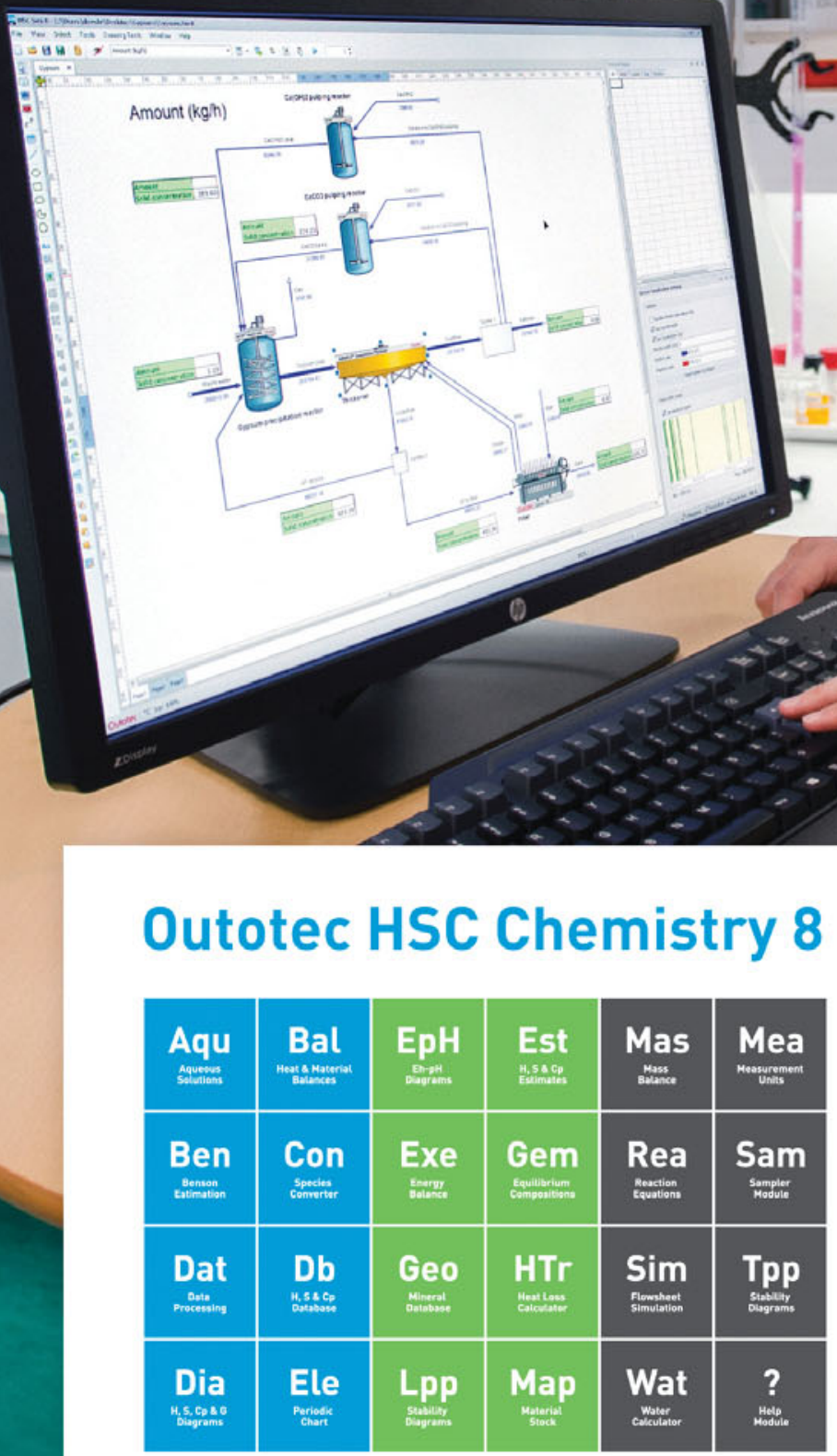

Outotec's chemical reaction and equilibrium software HSC Chemistry is the world's favorite thermochemical and mineralogical toolbox with a versatile flowsheet simulation module. All calculations and simulations are in an easyto-use format. The current version HSC 8 contains altogether 24 calculations modules and a database with over 28,000 chemical species.

hscRoutotec.com

www.outotec.com/HSC

Sustainable use of Earth's natural ressources 
dysprosium pellets

atomic layer deposition scandium-aluminum

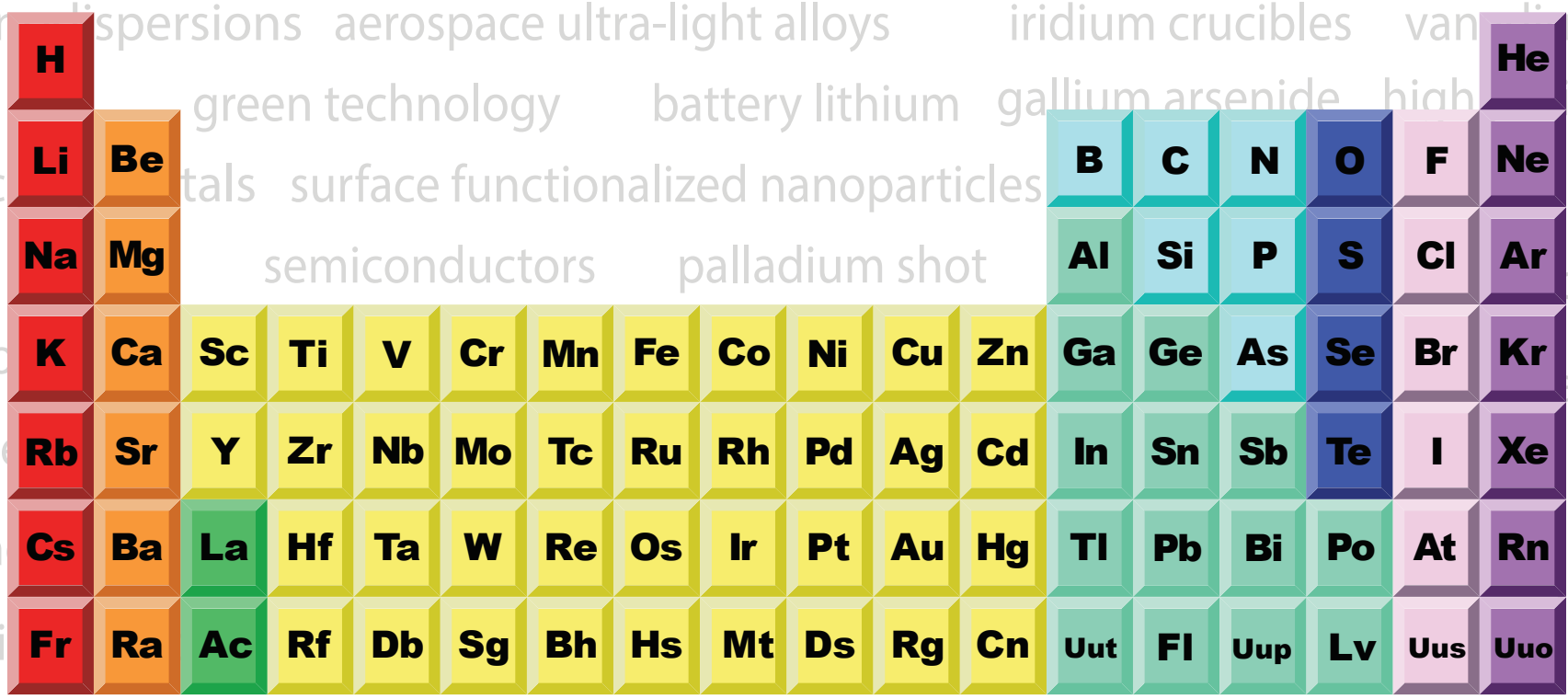

\begin{tabular}{|c|c|c|c|c|c|c|c|c|c|c|c|c|}
\hline Ce Pr & Nd & Pm & Sm & Eu & Gd & Tb & Dy & Ho & Er & Tm & $\mathbf{Y b}$ & Lu \\
\hline $\mathbf{P a}$ & $\mathbf{U}$ & $\mathbf{N p}$ & Pu & Am & $\mathrm{Cm}$ & Bk & Cf & Es & Fm & Md & No & Lr \\
\hline
\end{tabular}

nanofabrics rare earth metals nickelfoam LED lighting

platinum ink laser crystals

titanium robotic parts tungsten carbide

stable isotopes carbon nanotubes gold nanoparticles

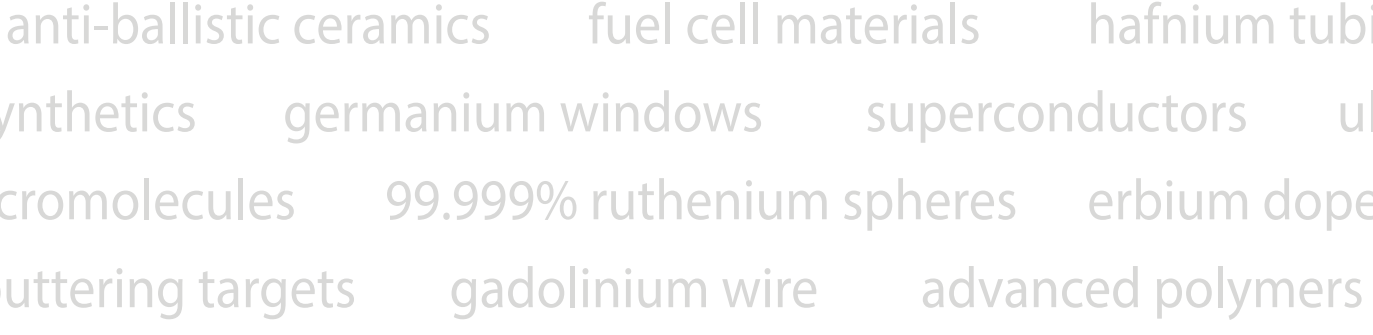

rhodium sponge shape memory alloys

alternative energy

\section{口CA M ER ICA N \\ ELEMENTS}

THE MATERIALS SCIENCE COMPANY $®$ catalog: americanelements.com

(C2001-2014. American Eements isaU.S. Registered Trademark. 